\title{
From simulation to experiment: Understanding BO-regeneration kinetics
}

\author{
Svenja Wilking ${ }^{\mathrm{a}, *}$, Maxime Forster ${ }^{\mathrm{b}}$, Axel Herguth ${ }^{\mathrm{a}}$, Giso Hahn ${ }^{\mathrm{a}}$ \\ a University of Konstanz, Department of Physics, P.O. Box 676, 78457 Konstanz, Germany \\ ${ }^{\mathrm{b}}$ ApollonSolar, 66 cours Charlemagne, 69002 Lyon, France
}

\section{A R T I C L E I N F O}

Keywords:

Silicon

Boron-oxygen

Regeneration

\begin{abstract}
A B S T R A C T
Regeneration of boron oxygen related defects is investigated in differently compensated silicon wafers. It is shown for the first time that boron oxygen defects can be transformed into a stable regenerated state also in compensated $\mathrm{n}$ type silicon.

The coupling between regeneration rate and the completeness of the regeneration reaction is simulated based on the 3 state model of BO defects. Maximum regeneration temperatures that can be applied are determined for differently regenerating samples. The results are used to develop a high speed process that can accelerate regeneration by two orders of magnitude without compromising neither the completeness of the regeneration process nor the stability of the resulting high minority carrier lifetime values.
\end{abstract}

\section{Introduction}

Boron doped crystalline silicon with high oxygen content, e.g., Czochralski $(\mathrm{Cz})$ grown silicon, shows severe minority carrier lifetime degradation under carrier injection due to boron oxygen related (BO) defects becoming recombination active [1 3]. This results in deterioration of lifetime sensitive devices made from these materials, e.g., crystalline silicon solar cells [ $\left.\begin{array}{ll}4 & 6\end{array}\right]$. The same effect occurs in boron doped $\mathrm{p}$ type [7 9] as well as $\mathrm{n}$ type $[10,11]$ silicon partially compensated or overcompensated with phos phorus or co doped with gallium. BO defects can be transformed into a recombination inactive state that is stable under carrier injection by the regeneration reaction that requires a combination of slightly elevated temperatures (typically $60200^{\circ} \mathrm{C}$ ) and carrier injection [12,13], applied to hydrogenated silicon wafers [14 16]. This reaction may be identified (after the first occurring degra dation reaction) by an asymptotically saturating recovery of the carrier lifetime or an asymptotical decrease of the defect density. For compensated p type silicon it has been shown that the regeneration process also works in $\mathrm{p}$ type samples co doped with boron and phosphorus [17 20] with the limitation that the resulting BO state seemed to be only partially stable $[19,20]$. On

\footnotetext{
*Corresponding author. Tel.: +49 7531883731; fax: +49 7531883895 .

E-mail addresses: Svenja.Wilking@uni-konstanz.de (S. Wilking),

Forster@apollonsolar.com (M. Forster),

Axel.Herguth@uni-konstanz.de (A. Herguth),

Giso.Hahn@uni-konstanz.de (G. Hahn).
}

the other hand, $\mathrm{n}$ type silicon doped with the same elements could not be successfully regenerated into a stable BO state [21].

Here, we present regeneration data measured in silicon wafers taken from $\mathrm{Cz}$ ingots that are (co )doped with differing amounts of boron, gallium and phosphorus resulting in $p$ type as well as in $n$ type samples. An adapted high speed regeneration process is developed based on the analysis of the interaction between the different transition reactions of the BO defect. The focus of this work is on the regeneration kinetics independent of the physical model that may explain the regeneration of recombination active BO defects.

\section{Three-state-model simulations}

The BO defect undergoes different transitions described by the 3 state model (see Fig. 1) that depend on the external conditions [22]. BO degradation leading to the well known reduction in minority carrier lifetime occurs in silicon under carrier injection if boron and oxygen are present in sufficiently high concentrations. Annealing as well as destabilization is purely thermally activated whereas regeneration additionally relies on carrier injection and the presence of hydrogen within the material, as introduced, e.g., via a belt furnace firing step from hydrogenated layers [23,24]. As long as low injection conditions are used, degradation is also only thermally activated when a certain minimum illumination ( $<0.1$ sun) is applied [25]. At typical regeneration conditions consisting of a combination of slightly elevated temperatures (e.g., $60230^{\circ} \mathrm{C}$ ) and carrier injection, all four transition reactions are 


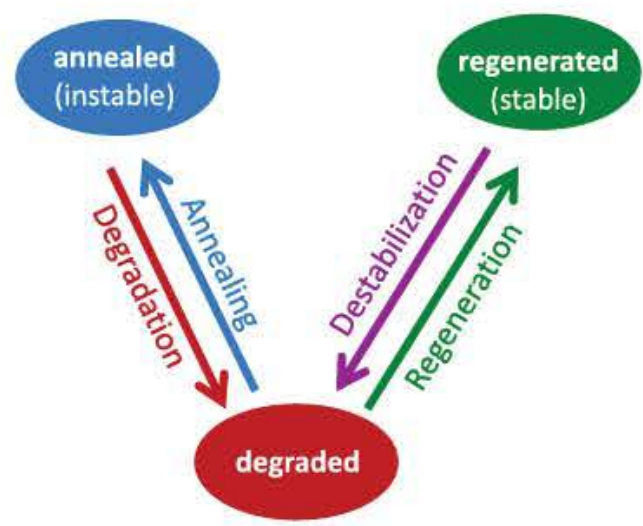

Fig. 1. Transition paths of the metastable BO defect. Annealing and destabilization occur in the dark, whereas degradation and regeneration only occur under carrier injection. All reactions are thermally activated.

Table 1

Thermal activation energy $E_{\mathrm{A}}$ and transition rates at $200^{\circ} \mathrm{C}$ used for simulation purposes. Time constant at temperatures deviating from $200{ }^{\circ} \mathrm{C}$ are altered according to Arrhenius' law.

\begin{tabular}{lll}
\hline & $E_{\mathrm{A}}(\mathrm{eV})$ & Rate at $200^{\circ} \mathrm{C}\left(\min { }^{1}\right)$ \\
\hline Annealing & $1.3[25,26]$ & $4.0[25]$ \\
Degradation & $0.4[27,28]$ & 15.5 (extrapol. from $\left.25^{\circ} \mathrm{C}\right)[27]$ \\
Regeneration & $1.0[30]$ & $0.03[29]$ (slow). $24.0[30]$ (fast) \\
Destabilization & $1.25[30]$ & $0.015[29]$ \\
\hline
\end{tabular}

active simultaneously. Hence, the rates of all of them determine how the occupancy of the three BO states evolves during such treatment. In the following section, this will be investigated by means of calculations using the 3 state model. The equations used for simulation purposes can be found in [22]. All transition reac tions are thermally activated, but differ considerably in activation energy (see Table 1). Hence, the influence of the four transition reactions on the evolution of the occupancy of the different defect states will be evaluated at different temperatures. The time con stants/transition rates at temperatures deviating from $200{ }^{\circ} \mathrm{C}$ are calculated according to Arrhenius' law. The activation energy of the regeneration reaction assumed for the simulation presented here was measured in uncompensated samples since there is no confirmed value for compensated wafers (see [19] for the only published value). Please note that regeneration rates can only be measured reliably if the regeneration process is complete and the resulting carrier lifetime is stable under further illumination at lower temperature. If this is not the case, the measured transition rate is very probably a superposition of the desired regeneration and an unwanted annealing reaction. Hence, neither the extracted rates nor activation energies calculated from such measurements can clearly be assigned to the regeneration of $\mathrm{BO}$ defects. The activation energy of the destabilization reaction has not been measured in compensated wafers, yet. Thus, the activation energy values for compensated samples might deviate slightly from the values assumed here without the basic message being changed.

\subsection{Influence of regeneration rate on $\mathrm{BO}$ kinetics}

In this section, the influence of different regeneration rates on BO kinetics is discussed. It is assumed that a silicon wafer con taining boron as well as oxygen is exposed to carrier injection at $200^{\circ} \mathrm{C}$. The simulation shown in Fig. 2 compares BO kinetics for fast $\left(R_{\text {Reg }}=24 \mathrm{~min}^{1}\right)$ and slowly $\left(R_{\text {Reg }}=0.03 \mathrm{~min}^{1}\right)$ regener ating samples keeping all other transitions constant. Experimen tally, this situation can be realized by comparing a well hydrogenated sample (regenerating quickly) to a poorly hydro genated one (regenerating slowly) or by changing the illumination intensity.

Apart from the latter samples reaching a stable distribution of BO states later, regeneration becomes incomplete in the slowly regenerating sample (Fig. 2, right): $\sim 40 \%$ of the defects stay either in the degraded or in the annealed state implicating that lifetime is not permanently stabilized at the intended high level. If the time resolved progress is not monitored, this effect may be mis interpreted in the way that the treatment duration was simply chosen to short, e.g., stopping it at $t=0.1 \mathrm{~min}$ in Fig. 2 (left) and treating the sample for longer times ( $>1 \mathrm{~min}$ ) would still lead to the intended result. However, as can be seen in Fig. 2 (right) for the shown slow regeneration rate, once the system has reached its final equilibrium state, extending the treatment duration will not change the situation. Besides, illumination at lower temperature would result in renewed degradation of the unintentionally annealed defects. This renewed degradation can be mistaken for the regenerated state to be instable.

When having a look at the equations describing the evolution of the different defect states (see [22] for details), it becomes clear why the regeneration rate at a given temperature influences the completeness of the actual regeneration process: If the destabili zation rate is in the same order of magnitude as the regeneration rate, e.g., for slowly regenerating samples, the regenerated $\mathrm{BO}$ state empties during the process to a considerable extent meaning that the long term equilibrium shifts away from the regenerated state. Thus, the occupancy of the regenerated state after saturation depends on the ratio of regeneration and destabilization rate meaning on the regeneration rate if temperature and therefore the destabilization rate is kept constant. Hence, the occupancy of the regenerated state in equilibrium changes with regeneration time constant and there exists a critical regeneration time constant for each temperature (e.g., $\sim 1 \mathrm{~min}$ at $200^{\circ} \mathrm{C}$, see Fig. 3 left) beyond which the regeneration process cannot be complete ( $>99 \%)$ anymore because regeneration is not fast enough compared to the destabilization reaction. To reach $99 \%$ complete regeneration, a ratio of at least $R_{\text {Reg }} / R_{\text {Dest }} \approx 100$ is needed. This ratio automatically decreases for slowly regenerating samples so that, e.g., in samples with a regeneration time constant of $50 \mathrm{~min}$ at $200^{\circ} \mathrm{C}$ only $50 \%$ of all $\mathrm{BO}$ defects can be transformed into the stable regenerated state, as depicted in Fig. 3.

\subsection{Consequences and limitations for high speed regeneration processes}

As explained in the last section, the completeness of the regeneration process depends on the ratio of regeneration $\left(R_{\mathrm{Reg}}\right)$ and destabilization $\left(R_{\text {Dest }}\right)$ rates. To reach $99 \%$ complete regen eration, a ratio of at least $R_{\text {Reg }} / R_{\text {Dest }} \approx 100$ is needed, $95 \%$ complete regeneration requires at least $R_{\text {Reg }} / R_{\text {Dest }} \approx 25$. Since destabilization has a higher $(>1.25 \mathrm{eV})$ activation energy than regeneration $(1.0 \mathrm{eV})$ (see Table 1), the ratio of their rates decreases auto matically with increasing temperature meaning that regeneration becomes more and more incomplete. Hence, temperature cannot be increased deliberately (without changing the sample proces sing or increasing illumination during the process). This is a very important result for industrial application of regeneration.

The maximum temperature that is possible without compro mising the regeneration completeness can be determined by the following procedure:

1. Measure the regeneration time constant of a specific sample at a temperature that is low enough for the regeneration to be measurable and complete, e.g., $130^{\circ} \mathrm{C}$. This will determine whether the sample is fast (time constant in the order of 

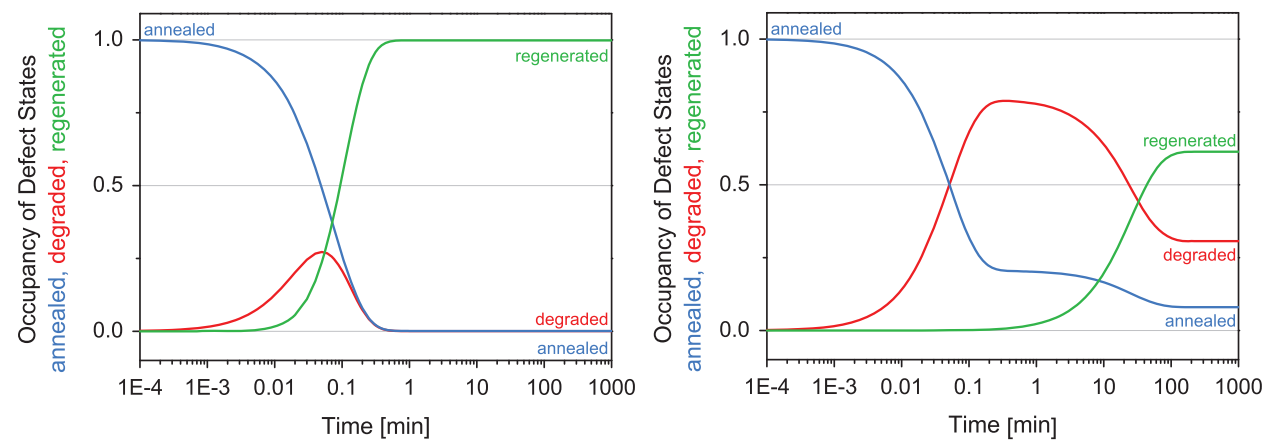

Fig. 2. Evolution of the occupancy of the different BO defect states during simulated regeneration treatment of Si wafers at $200{ }^{\circ} \mathrm{C}$ under carrier injection. (Left) Fast regenerating sample: saturates quickly at 100\% regeneration. (Right) Slowly regenerating sample: saturation is reached later and only $\sim 60 \%$ of all BO defects are in the regenerated state.
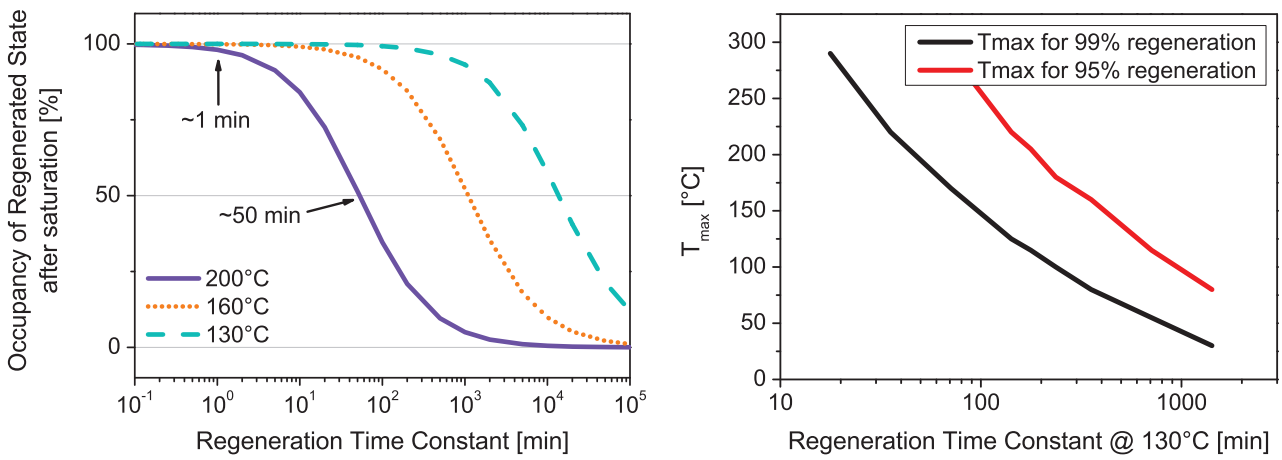

Fig. 3. (Left) At a given temperature, the regeneration time constant determines what ratio of BO defects is regenerated once equilibrium is reached. (Right) $T_{\text {max }}$ allowed for the regeneration process in dependence of regeneration time constant measured at $130^{\circ} \mathrm{C}, 1.1$ sun for $99 \%(95 \%)$ complete regeneration.

minutes at $130^{\circ} \mathrm{C}$ ) or slowly (time constant in the order of hours at $130{ }^{\circ} \mathrm{C}$ ) regenerating.

2. Extrapolate the regeneration time constant to higher tem peratures using the Arrhenius correlation. The destabilization time constant at the respective temperatures can be found in the literature [30] for several temperatures and can be extra polated the like.

3. Calculate $R_{\text {Reg }} / R_{\text {Dest }}(T) . \quad T_{\max }$ is the temperature where $R_{\text {Reg }} / R_{\text {Dest }}$ equals 100 (or any other desired value, e.g., 25 for 95\% completeness).

Fig. 3 (right) shows how far temperature can be increased in the case of samples featuring certain regeneration time constants at standard regeneration temperature of $130^{\circ} \mathrm{C}$ without reducing the completeness of the regeneration process.

These results are now used to understand the regeneration behavior of compensated $\mathrm{p}$ type as well as $\mathrm{n}$ type samples.

\section{BO-regeneration measurements in compensated silicon}

\subsection{Experimental details}

Samples investigated in this experiment are made from $\mathrm{Si}$ wafers differently doped with B, P and Ga. The dopant con centrations are given in Table 2. They were calculated using Scheil's equation; the interstitial oxygen concentrations were measured with FTIR (Fourier transformed infrared spectroscopy). All wafers were laser cleaved into smaller pieces, saw damage etched in hot $\mathrm{NaOH}$, followed by cleaning in $\mathrm{HCl}$ and dipping in diluted HF. Then, a $\mathrm{POCl}_{3}$ based gettering step was applied at high temperature $\left(\sim 1 \mathrm{~h}\right.$ at $\left.\sim 840^{\circ} \mathrm{C}\right)$. The diffused layer was removed thereafter in hot $\mathrm{NaOH}$. After RCA cleaning, a hydrogen rich PECVD
Table 2

Concentration of dopants and interstitial oxygen in the investigated samples.

\begin{tabular}{lllll}
\hline Sample & $\begin{array}{l}{[\mathrm{B}] \text { in }} \\
10^{16} \mathrm{~cm}^{3}\end{array}$ & $\begin{array}{l}{[\mathrm{P}] \text { in }} \\
10^{16} \mathrm{~cm}^{3}\end{array}$ & $\begin{array}{l}{[\mathrm{Ga}] \text { in }} \\
10^{16} \mathrm{~cm}^{3}\end{array}$ & $\begin{array}{l}{\left[\mathrm{O}_{\mathrm{i}}\right] \mathrm{in}} \\
10^{17} \mathrm{~cm}^{3}\end{array}$ \\
\hline B & 1.0 & 0.0 & 0.0 & 8 \\
$\mathrm{~B}+\mathrm{P}$ & 3.0 & 1.5 & 0.0 & 6 \\
B+P+Ga & 3.4 & 7.8 & 5.4 & 7 \\
n-Type & 5.7 & 12.2 & 5.0 & 8
\end{tabular}

$\mathrm{SiN}_{x}: \mathrm{H}$ was deposited on both sides (75 $\mathrm{nm}$ each) using the direct plasma, low frequency PECVD (Plasma Enhanced Chemical Vapor Deposition) technique in a Centrotherm system. Finally, all sam ples were fired in a belt furnace at around $800{ }^{\circ} \mathrm{C}$ peak tempera ture in order to activate the $\mathrm{SiN}_{x}: \mathrm{H}$ surface passivation and to release hydrogen from the layer into the silicon bulk. From every material, the so processed lifetime samples underwent a proce dure including the following steps:

$1 . \mathrm{BO}$ annealing at $225^{\circ} \mathrm{C}$ in the dark for $15 \mathrm{~min}$.

2.BO degradation at $40^{\circ} \mathrm{C}, 0.2$ sun illumination for $\sim 70 \mathrm{~h}$.

3.BO regeneration at $130^{\circ} \mathrm{C}, 1.1$ sun illumination (standard regeneration) or at $180^{\circ} \mathrm{C}, 2.7$ sun (high speed regeneration) until saturation of minority carrier lifetime.

4.Stability check of minority carrier lifetime at $45^{\circ} \mathrm{C}, 0.2$ sun for $24 \mathrm{~h}$.

Illumination was done by an incandescent halogen lamp. Effective minority carrier lifetime $\tau_{\text {eff }}(t)$ was measured after each step and every few minutes during the regeneration process at an injection of $10 \%$ of the doping level using a WCT 120 lifetime tester from Sinton Instruments. Lifetime values were transformed into normalized $\mathrm{BO}$ defect concentrations $N^{*}(t)$ using $N^{*}(t)=1 / \tau(t) \quad 1 / \tau_{\text {ann }}$ with the life time in the annealed state $\tau_{\text {ann }}$ not being affected by BO defects. $N^{*}(t)$ is fitted using a single exponential function yielding the characteristic 

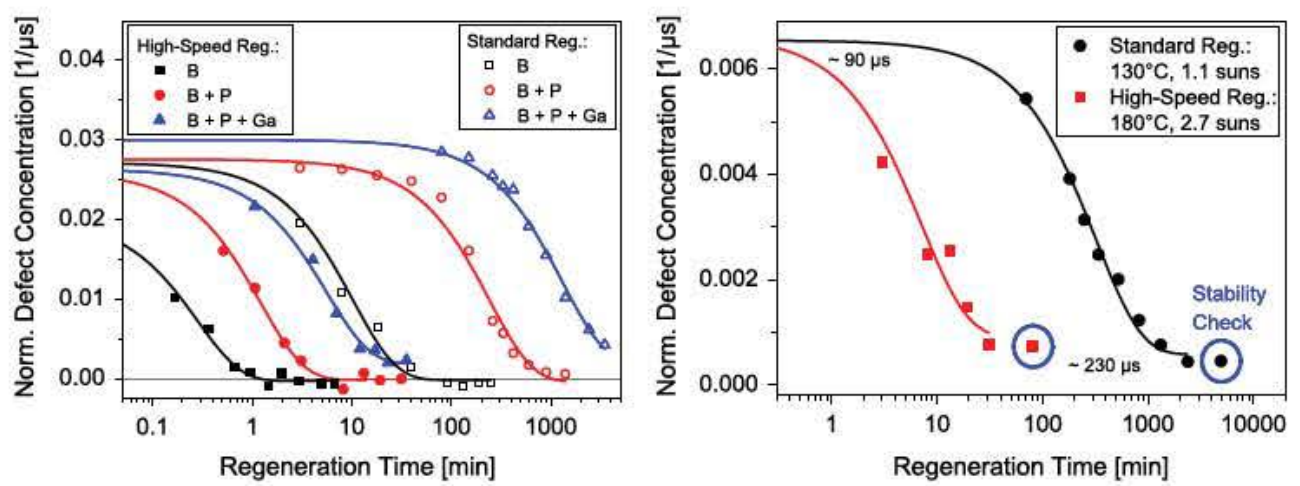

Fig. 4. Evolution of $\mathrm{BO}$ defect concentration during a standard $\left(130^{\circ} \mathrm{C}, 1.1 \mathrm{sun}\right.$; open symbols) and an adapted high-speed (180 ${ }^{\circ} \mathrm{C}$, 2.7 sun; filled symbols) regeneration process for p-type (left) and n-type (right) compensated silicon (different scaling!). The latter process leads to acceleration of the regeneration reaction by two orders of magnitude. The stability of the regenerated state has been proven for all samples.

regeneration time constant $t_{\text {Reg }}$ and its inverse, the regeneration rate $R_{\text {Reg, }}$ that are both used to compare the regeneration kinetics of different samples. To get a time resolved measurement of the high speed regeneration process, the respective samples were degraded at $45^{\circ} \mathrm{C}, 0.2$ sun until saturation after each regeneration step to ensure that no defects were unintentionally transformed into the instable annealed state that would at first glance result in the same increasing lifetime values. After that, minority carrier lifetime is measured and its evolution with time is analyzed as for the standard regeneration process.

\subsection{Results}

Fig. 4 shows the evolution of the BO defect concentration during the standard $\left(130^{\circ} \mathrm{C}, 1.1 \mathrm{sun}\right)$ and an adapted high speed regenera tion process that is characterized by the use of higher temperature and stronger illumination $\left(180^{\circ} \mathrm{C}, 2.7\right.$ sun). At first glance, a tendency can be seen that the non compensated samples regenerate the most quickly $\left(R_{\text {Reg }} \approx 27 \mathrm{~h}{ }^{1}\right.$ ), followed by the samples partially com pensated with phosphorus ( $R_{\mathrm{Reg}} \approx 0.40 .7 \mathrm{~h}{ }^{1}$ ) and finally by the samples additionally containing gallium $\left(R_{\mathrm{Reg}} \approx 0.010 .15 \mathrm{~h}^{1}\right)$. Their regeneration rates differ from the first and the second group by one, respectively two orders of magnitude. Minority carrier lifetime of all regenerated samples is stable under further illumination $(0.2$ sun, $45^{\circ} \mathrm{C}$ ). The same is true for the $\mathrm{n}$ type compensated samples and in both cases the high speed process allows acceleration of the regen eration reaction by two orders of magnitude. Hence, our procedures are suited to regenerate successfully $\mathrm{BO}$ defects in both $\mathrm{p}$ and $\mathrm{n}$ type compensated silicon and the final state is characterized by high lifetime and stability under carrier injection.

The general trend found by Lim et al. [18] saying that regeneration is slowed down by increasing boron concentrations can be con firmed. This is what one would expect if the regeneration of BO defects can be explained by mobile hydrogen atoms passivating the recombination active defects because boron is known to trap hydrogen [31 and many others]. Hence, increasing boron con centration decreases the concentration of mobile hydrogen atoms within the wafer and can reduce its diffusivity. Therefore, higher boron concentrations would result in a slower regeneration process. But more data is needed to investigate a possible additional influence of phosphorus or gallium on the regeneration of BO defects. This question will be addressed in a separate publication [32].

The regenerated state being stable under illumination in $\mathrm{n}$ type silicon has direct consequences on the physical model of the BO regeneration. Sun et al. [33] explained that in $\mathrm{n}$ type $\mathrm{Si}$ the regenerated state could not be stable under carrier injection if regeneration is ionic interaction between hydrogen and $\mathrm{BO}$ defects. Since Niewelt et al. [34] recently presented convincing data on the long time stability of the minority carrier lifetime of
BO regenerated compensated $\mathrm{n}$ type wafers under illumination, we can conclude that the deactivation may rather be achieved by covalent binding between hydrogen and BO defect than by ionic interaction. Another explanation would be hydrogen having a catalytic effect on BO regeneration. See [34] for details.

\subsection{Adapting the high speed regeneration process}

The non compensated samples presented in this paper regener ate fast enough $\left(t_{\operatorname{Reg}} \approx 45 \mathrm{~min}\right.$ at $\left.130^{\circ} \mathrm{C}\right)$ for the regeneration tem perature to be increased to $T_{\max }>200^{\circ} \mathrm{C}$. In contrast, for the samples compensated with boron and phosphorus, $t_{\text {Reg }}$ is $\sim 120 \mathrm{~min}$ at $130^{\circ} \mathrm{C}$ which corresponds to $T_{\max } \approx 130^{\circ} \mathrm{C}$. Hence, temperature cannot be increased unless regeneration is additionally enhanced: Increasing the illumination intensity can compensate for otherwise decreasing completeness at higher regeneration temperature. E.g., using 2.7 sun illumination instead of 1.1 sun can halve the regeneration time con stant. Then, temperature can be increased to $\sim 180^{\circ} \mathrm{C}$ without pro blems. Therefore, the high speed regeneration process is adapted to these conditions and is carried out at $180^{\circ} \mathrm{C}, 2.7 \mathrm{sun}$. As a matter of fact, samples that regenerate even more slowly, e.g., the $\mathrm{p}$ and $\mathrm{n}$ type samples co doped with B, Ga and P, cannot regenerate com pletely under those conditions. This can be seen in Fig. 4, where the samples co doped with boron, gallium and phosphorus saturate at a defect concentration level that is above zero.

\subsection{Discussion on "incomplete" regeneration processes}

The correlation between regeneration rate and its complete ness can also explain why earlier studies $[19,21]$ found that min ority carrier lifetime was not stable after "regeneration" of com pensated $\mathrm{p}$ and $\mathrm{n}$ type silicon. The "regeneration" process typi cally was carried out at $\sim 200^{\circ} \mathrm{C}, 1$ sun [21]. The determined regeneration rates in the order of $12 \mathrm{~h}$ at $200{ }^{\circ} \mathrm{C}$, e.g., due to poor hydrogenation of the silicon bulk, are apparently to slow to apply such high regeneration temperatures without compromising the completeness of the regeneration process, and a considerable number of BO defects will unintentionally transform into the instable annealed state. Hence, a following stability test under degradation conditions (e.g. $45^{\circ} \mathrm{C}, 0.2$ sun) would again lead to $\mathrm{BO}$ related degradation of the latter defect species; but this does not mean that the regenerated BO state is instable itself. This problem becomes the more important the lower the regeneration rates are within a sample, hence it might even seem as if regeneration was impossible in the extremely slowly regenerating compensated $n$ type samples [21].

As opposed to this, in the investigations presented here, we applied two regeneration procedures that both meet the require ments for complete regeneration: a standard low temperature 
regeneration process at $130{ }^{\circ} \mathrm{C}, 1.1$ sun illumination and a high speed regeneration process at $180^{\circ} \mathrm{C}, 2.7$ sun illumination, both carried out on hydrogenated samples.

\section{Summary and conclusions}

The regeneration of $\mathrm{BO}$ defects was investigated in hydro genated lifetime samples made from differently compensated $\mathrm{p}$ and $\mathrm{n}$ type silicon wafers.

A procedure that is able to transform BO related defects into the regenerated state characterized by high lifetime and stability under subsequent illumination was presented for the first time for $\mathrm{n}$ type compensated silicon. Comparable to $\mathrm{p}$ type samples, the regeneration process could be accelerated by two orders of magnitude by applying an adapted high speed regeneration pro cedure. No differences in the stability of the regenerated state or in the completeness of the regeneration process were found on condition of choosing suitable regeneration parameters. Those parameters were determined by simulating the influence of dif ferent regeneration rates on the completeness of the regeneration process based on the 3 state model of BO defects. Maximum regeneration temperatures that can be applied were determined depending on the regeneration rate measured at standard regen eration conditions $\left(130^{\circ} \mathrm{C}\right)$. The results were used to adapt the high speed regeneration process without compromising neither the completeness of the regeneration process nor the stability of the resulting high minority carrier lifetime values.

\section{Acknowledgments}

The authors would like to thank ApollonSolar for providing the Si material, L. Mahlstaedt and T. Wiedenmann for technical sup port during sample preparation and S. Stoyanov for regeneration measurements. Part of this work was funded by the German BMU under Contracts 0325581 and 0325450A. The content is the responsibility of the authors.

\section{References}

[1] H. Fischer, W. Pschunder, Investigation of photon and thermal induced changes in silicon solar cells, in: Proc. 10th IEEE PVSC, Palo Alto, USA (1973) p. 404.

[2] J. Knobloch, S.W. Glunz, D. Biro, W. Warta, E. Schaffer, W. Wettling, Solar cells with efficiencies above $21 \%$ processed from Czochralski grown silicon, in: Proc. 25th IEEE PVSC, New York, USA (1996) p. 405.

[3] J. Schmidt, A.G. Aberle, Accurate method for the determination of bulk minority-carrier lifetimes of mono-and multicrystalline silicon wafers, J. Appl. Phys. 81 (1997) 6186.

[4] S.W. Glunz, S. Rein, W. Warta, J. Knobloch, W. Wettling, Degradation of carrier lifetime in Cz silicon solar cells, Sol. Energy Mater. Sol. Cells 65 (2001) 219.

[5] K. Bothe, J. Schmidt, Electronically activated boron-oxygen-related recombination centers in crystalline silicon, J. Appl. Phys. 99 (2006) 013701.

[6] V.V. Voronkov, R. Falster, Latent complexes of interstitial boron and oxygen dimers as a reason for degradation of silicon-based solar cells, J. Appl. Phys. 107 (2010) 053509

[7] S. Dubois, N. Enjalbert, J.P. Garandet, Slow down of the light-induced-degradation in compensated solar-grade multicrystalline silicon, Appl. Phys. Lett. 93 (10) (2008) 103510

[8] M. Forster, E. Fourmond, F.E. Rougieux, A. Cuevas, R. Gotoh, K. Fujiwara, M. Lemiti, Boron-oxygen defect in Czochralski-silicon co-doped with gallium and boron, Appl. Phys. Lett. 100 (4) (2012) 042110.
[9] D. Macdonald, F. Rougieux, A. Cuevas, B. Lim, J. Schmidt, M. Di Sabatino, L. J. Geerligs, Light-induced boron-oxygen defect generation in compensated ptype Czochralski silicon, J. Appl. Phys. 105 (2009) 093704.

[10] T. Schutz-Kuchly, J. Veirman, S. Dubois, D. Heslinga, Light-induced-degradation effects in boron-phosphorus compensated n-type Czochralski silicon, Appl. Phys. Lett. 96 (2010) 1.

[11] F.E. Rougieux, B. Lim, J. Schmidt, M. Forster, D. Macdonald, A. Cuevas, Influence of net doping, excess carrier density and annealing on the boron oxygen related defect density in compensated n-type silicon, J. Appl. Phys. 110 (2011) 063708.

[12] A. Herguth, G. Schubert, M. Kaes, G. Hahn, A new approach to prevent the negative impact of the meta-stable defect in boron doped $\mathrm{Cz}$ silicon solar cells, in: Proc. 32nd IEEE PVSC (4th WCPEC), Waikoloa, USA (2006) p. 940.

[13] A. Herguth, G. Schubert, M. Kaes, G. Hahn, Investigations on the long time behavior of the metastable boron-oxygen complex in crystalline silicon, Prog. Photovolt.: Res. Appl. 16 (2008) 135.

[14] K.A. Münzer, Hydrogenated silicon nitride for regeneration of light induced degradation, in: Proc. 24th EUPVSEC, Hamburg, Germany (2009) p. 1558.

[15] G. Krugel, W. Wolke, J. Geilker, S. Rein, R. Preu, Impact of hydrogen concentration on the regeneration of light induced degradation, Energy Procedia 8 (2011) 47.

[16] S. Wilking, A. Herguth, G. Hahn, Influence of hydrogen on the regeneration of boron-oxygen related defects in crystalline silicon, J. Appl. Phys. 113 (2013) 194503.

[17] S. Dubois, N. Enjalbert, J.P. Garandet, R. Monna, J. Kraiem, Light-induced degradation and regeneration in compensated upgraded metallurgical silicon, in: Proc. 23th EUPVSEC, Valencia, Spain, (2008) p. 1437.

[18] C. Xiao, X. Yu, D. Yang, D. Que, Study on permanent deactivation of the lightinduced degradation in p-type compensated crystalline silicon solar cells, Sol. Energy Mater. Sol. Cells 117 (2013) 29.

[19] B. Lim, A. Liu, D. Macdonald, K. Bothe, J. Schmidt, Impact of dopant compensation on the deactivation of boron-oxygen recombination centers in crystalline silicon, Appl. Phys. Lett. 95 (2009) 232109.

[20] R. Sondena, A. Holt, A.K. Soiland, Electrical properties of compensated n- and p-type monocrystalline silicon, in: Proc. 26th EUPVSEC, Hamburg, Germany (2011) p. 1824.

[21] B. Lim, Boron-oxygen related recombination centers in crystalline silicon and the effects of dopant-compensation, Dissertation, Hannover (2012).

[22] A. Herguth, G. Hahn, Kinetics of the boron-oxygen related defect in theory and experiment, J. Appl. Phys. 108 (2010) 114509.

[23] S. Wilking, S. Ebert, A. Herguth, G. Hahn, Influence of hydrogen effusion from hydrogenated silicon nitride layers on the regeneration of boron-oxygen related defects in crystalline silicon, J. Appl. Phys. 114 (2013) 194512.

[24] S. Wilking, J. Engelhardt, S. Ebert, C. Beckh, A. Herguth, G. Hahn, High speed regeneration of BO-defects: improving long-term solar cell performance within seconds, in: Proc. 29th EUPVSEC, Amsterdam, Netherlands (2014) p. 366.

[25] J. Schmidt, K. Bothe, Structure and transformation of the metastable boronand oxygen-related defect center in crystalline silicon, Phys. Rev. B 69 (2004) 024107.

[26] S. Rein, T. Rehrl, W. Warta, S.W. Glunz, G. Willeke, Electrical and thermal properties of the metastable defect in boron-doped Czochralski silicon (Cz-Si), in: Proc. 17th EUPVSEC, Munich, Germany (2002) p. 1555.

[27] J. Schmidt, K. Bothe, R. Hezel, Formation and annihilation of the metastable defect in boron-doped Czochralski silicon, in: Proc. 29th IEEE PSVC (2002) p. 178.

[28] S. W. Glunz, E. Schäffer, S. Rein, K. Bothe, J. Schmidt, Analysis of the defect activation in $\mathrm{Cz}$ silicon by temperature dependent bias-induced degradation of solar cells, in: Proc. 3rd WCPEC (2003) p. 919.

[29] B. Lim, K. Bothe, J. Schmidt, Accelerated deactivation of the boron-oxygenrelated recombination centre in crystalline silicon, Semicond. Sci. Technol. 26 (2011) 095009.

[30] S. Wilking, C. Beckh, S. Ebert, A. Herguth, G. Hahn, Influence of bound hydrogen states on BO-regeneration kinetics and consequences for high-speed regeneration processes, Sol. Energy Mater. Sol. Cells 1 (2014) 2-8.

[31] J.I. Pankove, P.J. Zanzucchi, C.W. Magee, G. Lucovs, Hydrogen localization near boron in silicon, Appl. Phys. Lett. 46 (1985) 421.

[32] S. Wilking, M. Forster, G. Hahn, Regeneration of boron-oxygen related defects in compensated crystalline silicon, to be published.

[33] C. Sun, F.E. Rougieux, D. Macdonald, A unified approach to modelling the charge state of monatomic hydrogen and other defects in crystalline silicon, J. Appl. Phys. 117 (2015) 045702.

[34] T. Niewelt, J. Broisch, J. Schön, J. Haunschild, S. Rein, W. Warta, M.C. Schubert, Light-induced degradation and regeneration in n-type silicon, Energy Procedia (2015), Accepted for publication. 